\title{
Case Report-Progressive immobilising back and joint pain
}

\section{Titus Divala ${ }^{1}$, Jamie Rylance ${ }^{2}$}

1.Department of Surgery, College of Medicine, University of Malawi

2. Malawi-Liverpool-Wellcome Trust Clinical Research Laboratories

Correspondence to: JR (jamie.rylance@liverpool.ac.uk)

\section{Case history}

A 29 years old male presented to our hospital with a three week history of left foot and left knee swelling. This was followed a week later by lower back, hip and bilateral lower chest pains. In the third week of illness, his walking became impaired due to his limb pain, and due to increasing difficulty in fully extending his neck. These symptoms were worse in the early morning, and initially eased over a few hours. This deteriorated, and by the time he presented to hospital he was confined to bed for most of the day. There was no preceding history of rash, dyspnoea, cough or gastrointestinal disturbance. Vision was subjectively normal, and he reported no ocular problems. Constitutionally, he was well with no weight loss or night sweats.

He had presented in a similar manner on a number of occasions within the preceding seven years. These episodes were typically characterised by lower back pain, large joint swelling and stiffness. Some appeared to have been self limiting, while during others he had been variously treated with non-steroidal anti inflammatory agents, and systemic corticosteroids. The last episode was eighteen months prior to presentation: at that time there was very little chest involvement and completely no neck involvement. Although between periods of illness he was able to return to work, there appeared to be a progressive decline in function. He was worried about his job security as a builder and subsistence farmer.

Past medical history was unremarkable, with no previous surgery or hospital admission. He had never smoked and did not drink alcohol.

He had attended school for six years and had three well children. A single family member (his paternal uncle) complained of recurrent joint pain and swelling of both knees, but had never sought medical attention for this.

On examination he held his neck in mid flexion which minimised otherwise severe pain. His vital signs were: blood pressure: 110/76 $\mathrm{mmHg}$; pulse $96 / \mathrm{min}$, regular and full volume; temperature $36 \mathrm{OC}$; respiratory rate $18 / \mathrm{min}$. There was no evidence of anaemia, lymphadenopathy or mucosal lesions. His nutritional status was poor (BMI 16.0).

In the lumbar spine, movements in all planes were reduced. For comfort, he used pillows to support his thoracic spine whilst lying. Both knees were swollen and felt warm. On the left, there was limited flexion, and full extension was not possible. There was similar, though less severe limitation on the right. There were no clinically detectable effusions by patella tap, no joint line tenderness, and no crepitus on passive movement. The hips and left ankle were also affected by limited range of active movement. There was an effusion of the right index metacarpophalyngeal joint, but no involvement of any other small joints.

Chest expansion was bilaterally subjectively reduced. Otherwise, clinical examination of the chest and abdomen was normal. Fingernails were normal, there were no peripheral stigmata of infective endocarditis. He was not confused, and had no neurological deficit in his limbs.

Radiography of the cervical spine was normal. The lumbar spine demonstrated fusion of the spinous processes of L2L4. There was evidence of inflammatory change of the sacroiliac joints bilaterally, with loss of joint space (see Figure 1). No other radiographs were taken. He was HIV negative. Full blood count showed: Hb 10.7, WCC 10.3, Pl 328. White cell differential was unavailable.

He was treated with oral prednisolone $40 \mathrm{mg} /$ day and aspirin 600mg qid for his joint disease. Further analgesia was given in the form of oramorph to allow early mobilisation. Additionally, omeprazole was added as prophylaxis against peptic ulceration.

Over the course of the next week, he became independently mobile, and was discharged home with instructions to taper his prednisolone to $10 \mathrm{mg}$. He was next seen six weeks later in clinic, having run out of medication and been unable to travel earlier due to lack of funds. At this point, although there was no joint swelling, back pain was considerable.

Spirometry performed as an outpatient showed: FEV1 1.78 (60\% of predicted), FVC 1.85 (53\% predicted), PEFR 7.77 ( $92 \%$ predicted), FEV1/FVC 0.96. Lung volumes and gas transfer were not available. We were unable to test for rheumatoid factor or other immunological markers.

Figure 1: Plain AP radiograph of the sacroiliac joints and lumbar spine

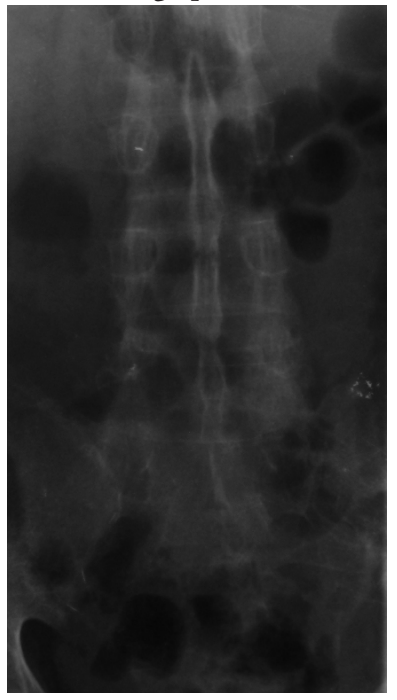

\section{Questions}

\section{What is the likely diagnosis, and what are other possibilities?}

\section{How could you account for the spirometry findings?}

\section{What would be the treatment of choice?}

\section{Discussion}

Our patient demonstrated a slowly progressive inflammatory disorder of the joints, starting in the third decade of life and predominantly affecting the axial skeleton and large joints. This was associated with loss of function due to pain and 
stiffness of the spine which affected his ability to work.

Rheumatoid arthritis (RA) would be consistent with but not typical for most of the presenting features. Notably, unlike typical RA, he had asymmetric joint involvement and minimal hand involvement. Indeed, he did not meet the American College of Rheumatology diagnostic criteria for RA. Other acute inflammatory diseases such as Reiter's syndrome (reactive arthritis) tend not to progress over this time frame. Although psoriatic arthropathy can precede skin lesions (in approx $6 \%$ of cases) ${ }^{1}$ and does infrequently involve sacroiliac joints, we considered this unlikely due to the 7 year history in our patient. Gout may be polyarticular but very rarely affects the axial skeleton. Septic arthritis tends to be monoarticular, would be more rapidly progressive and usually associates with fever. There was no other focus of infection, and infective endocarditis was not clinically apparent. Inflammatory bowel disease may cause sacroiliitis (particularly Crohn's disease) which is often independent of gastrointestinal symptoms ${ }^{2}$. However, there was no previous history of gastrointestinal pathology.

Supportive of our final diagnosis of ankylosing spondylitis (AS) was his age, predominant involvement of the axial skeleton and lumbar radiograph appearance. Additionally, although restrictive lung function patterns may in some patients reflect interstitial pulmonary fibrosis, the spirometry is consistent with reduced chest wall movement. The patient met the modified New York criteria for AS. These were created to support the clinical diagnosis (see Table 1), and avoid earlier problems of overlap with other seronegative spondyloarthropathies ${ }^{3}$, although the use of radiological features may delay diagnosis ${ }^{4}$.

\section{Table 1: Modfied Newyork criteria for AS}

\begin{tabular}{|c|c|}
\hline Cilinical & 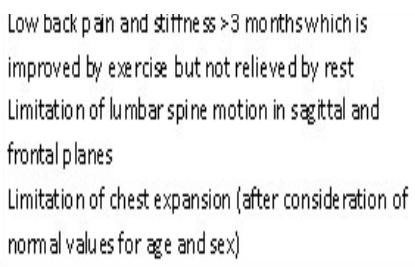 \\
\hline Radiolog gal evidence of sacroilitis & $\begin{array}{l}\text { = Grade } 2 \text { bildterally (sclerosis with some erosion) } \\
=\text { Grade } 3 \text { unilaterally (severe erosons, } \\
\text { psuedodd latation of the joint space and partial } \\
\text { anklyosis) }\end{array}$ \\
\hline \multicolumn{2}{|c|}{ A 'definite' diagnosis of ankylosing spondylitis requires 1 radiological criterion and 1 clinica criterion. } \\
\hline
\end{tabular}

Rheumatoid factor would be useful it is positive in three quarters of RA cases, but not in AS. Conversely, HLA-B27 is ten times more common in AS then $\mathrm{RA}^{5}$ in US populations. These rates may not be correct for our population however; ankylosing spondylitis in sub-Saharan Africa presents differently, at least in part due to lower prevalence of the HLA-B27 antigen. Such cases are less likely to have an affected family member, are milder in severity and have a lower rate of extra-articular features including anterior uveitis ${ }^{6}$.

The effective management of AS is multidisciplinary. Where possible, rheumatologists, physiotherapists ${ }^{7}$, and nonmedical support group should be engaged. Other specialty consultation is required where complications are suspected. These include: uveitis (20-30\%); aoritis leading to aortic regurgitation $(10 \%)$; cardiac conduction defects; pulmonary fibrosis (particularly of the upper zones); amyloidosis (with potential for renal involvement); osteoporosis and increased rates of bone fracture.

Currently there are no preventive measures or definitive treatment for AS. Medical treatment consists of pain and inflammation controllers and disease modifying drugs including tumournecrosis factor alpha ( $T N F \alpha$ ) blockers. Nonsteroidal anti-inflammatory drugs and opioids are commonly used to reduce pain and decrease inflammation. Where possible, steroids are not used for long-term management of AS because of the high risk of adverse effects. Sulfasalazine, methotrexate and newer anti-inflammatory drugs are in use to modify disease progression. Based on two Cochrane systematic reviews, sulfasalazine eases morning stiffness but there is no evidence of benefit on physical function or pain ${ }^{8}$ Methotrexate has little or no benefit? ${ }^{9}$ The TNF $\alpha$ antagonists such as etanercept, infliximab and adalimumab slow the progress of AS and in the majority of clinical cases this improves quality of life by the reduction, though not elimination, of the inflammation and pain. The progression of the disease and the effectiveness of treatment is monitored by serial measurement of inflammatory markers (such as the erythrocyte sedimentation rate [ESR] or C-reactive protein [CRP]).

In this case, methotrexate was initiated as a steroid sparing agent as no other appropriate drugs were available. Despite this, he presented on a number of occasions when his prednisolone was reduced. He remains on a maintenance dose of $10 \mathrm{mg} /$ day. Bone protective bisphosphonates are unavailable. Presently, there are no overt signs of Cushing's syndrome and he is able to continue working as a builder.

\section{References}

1. Wilson FC, Icen M, Crowson CS, McEvoy MT, Gabriel SE, Kremers HM. Time trends in epidemiology and characteristics of psoriatic arthritis over 3 decades: a population-based study. J Rheumatol. 2009 Feb;36(2):361-7.

2. Vavricka SR, Brun L, Ballabeni P, Pittet V, Prinz Vavricka BM, Zeitz $\mathrm{J}$, et al. Frequency and risk factors for extraintestinal manifestations in the Swiss inflammatory bowel disease cohort. Am J Gastroenterol. 2011 Jan;106(1):110-9.

3. Goie The HS, Steven MM, van der Linden SM, Cats A. Evaluation of diagnostic criteria for ankylosing spondylitis: a comparison of the Rome, New York and modified New York criteria in patients with a positive clinical history screening test for ankylosing spondylitis. Br J Rheumatol. 1985 Aug;24(3):242-9.

4. Rudwaleit M, Khan MA, Sieper J. The challenge of diagnosis and classification in early ankylosing spondylitis: do we need new criteria? Arthritis Rheum. 2005 Apr;52(4):1000-8.

5. Benedek TG. How did ankylosing spondylitis become a separate disease? Clin Exp Rheumatol. 2009 Jul-Aug;27(4 Suppl 55):S3-9.

6. Belachew DA, Sandu N, Schaller B, Guta Z. Ankylosing spondylitis in sub-Saharan Africa. Postgrad Med J. 2009 Jul;85(1005):353-7.

7. Dagfinrud H, Kvien TK, Hagen KB. Physiotherapy interventions for ankylosing spondylitis. Cochrane Database Syst Rev. 2008(1):CD002822.

8. Chen J, Liu C. Sulfasalazine for ankylosing spondylitis. Cochrane Database Syst Rev. 2005(2):CD004800.

9. Chen J, Liu C, Lin J. Methotrexate for ankylosing spondylitis. Cochrane Database Syst Rev. 2006(4):CD004524. 